\title{
Fungal spread and faecal decomposition as indicators to evaluate short term environmental impact of egg parasitic fungi Paecilomyces lilacinus and Verticillium chlamydosporium
}

\author{
Rupesh Kumar Singh and Prabir Kumar Sanyal* \\ Veterinary College, Anjora, Durg, Chhattisgarh, India. \\ * Corresponding author
}

\begin{abstract}
Experiments were conducted to understand the extent of spread of Paecilomyces lilacinus and Verticillium chlamydosporium once deposited in faeces and alteration, if any, of the organic content of faeces by them, which could serve as evidences of their short-term environmental impact. Coproculture of the central part and two concentric rings of both the fungus contaminated plots were undertaken twice a week for four weeks in laboratory for the presence of $P$. lilacinus and $V$. chlamydosporium. Subcultures were done until the confirmation of desired fungus occur. Paecilomyces lilacinus could not be reisolated from the central part and two concentric rings at any point of sampling period except from the faecal sample of the central part on day 0. Verticillium chlamydosporium could be re-isolated from the faeces deposited at the central part on day 0,7 and 14 but never from $21^{\text {st }}$ day of sampling onward. However, $V$. chlamydosporium could not be recovered from the faeces of two concentric rings at any point of sampling. Moisture contents decreased with corresponding increase in dry matter content of the faeces as the time progressed. Faeces mixed with P. lilacinus, $V$. chlamydosporium and no fungus controls behaved similarly in terms of moisture and dry matter contents. From $60^{\text {th }}$ day of deposition onwards, ash contents of faeces mixed with P. lilacinus, V. chlamydosporium and no fungus controls showed increasing trend with the corresponding decreasing trends in organic matter contents.

Keywords: Paecilomyces lilacinus, Verticillium chlamydosporium, fungal spread, faecal decomposition, environmental impact
\end{abstract}

\section{I ntroduction}

In the wake of wide-spread anthelmintic resistance in ruminant livestock, residues in food, environmental degradation and consumer demand for chemical free food and food products the world over (Waller, 1993) including India (Sanyal, 1998), work on the alternative strategies to control helminth parasites of grazing livestock is initiated the world over, biological control by predacious fungi is one of them. Biological control is aimed at exploiting natural enemies to reduce the number of target organisms to a level less than what would have occurred in the absence of the predators. Egg-parasitic fungi are one of the potent candidates for biological control. Egg parasitic fungi are characterized by their ability to colonise in parasite cysts and eggs. They generally attack by penetrating the eggs using specialized perforating structures or lateral branches from the mycelium (Stirling, 1991).

Recently, two egg-parasitic fungi namely Paecilomyces lilacinus and Verticillium chlamydosporium were isolated from the organic environment of the Chhattisgarh region in India (Sanyal et al., 2008) and were screened for in vitro growth using different media types, range of incubation temperature and $\mathrm{pH}$ and their predatory activity to the eggs of Fasciola gigantica and Gigantocotyle explanatum
(De etal., 2008).

One of the main requirements of a biological control agent is that it should have no effect on its immediate environment. While recommending the use of predacious fungi for biological control of animal parasites as the pre-parasitic stages on faeces and pasture, it is necessary to estimate the possible impact of the biocontrol agent on pasture ecosystem (Larsen, 1999). Spread of the fungus in the surrounding environment from its place of deposition and dung decomposition rate could be useful parameters in measuring any adverse effect of egg parasitic fungi on the environment (Sommer et al., 1992). The present investigations were thus, carried out with the Indian isolates of $P$. lilacinus and $V$. chlamydosporium to determine how long these egg parasitic fungi survive in the organic environment of faeces, how far they spread once deposited in the faecal pat and the alteration, if any, of organic content of faeces over a period of time.

\section{Materials and Methods}

Solid substrate fungal cultures: Wild strains of $P$. lilacinus and V. chlamydosporium isolated from Durg, Chhattisgarh, India, were established on $2.5 \%$ corn meal agar petri plates $(90 \mathrm{~mm}$ disposable and radiation 
Fungal spread and faecal decomposition as indicators to evaluate environmental impact of egg parasitic fungi

Table-1. Reisolation of egg parasitic fungi from faeces mixed with millet grain cultures of $P$. lilacinus $(\mathrm{PI})$ and $\mathrm{V}$. chlamydosporium $(\mathrm{Vc})$ in central parts and two concentric rings of pasture plots

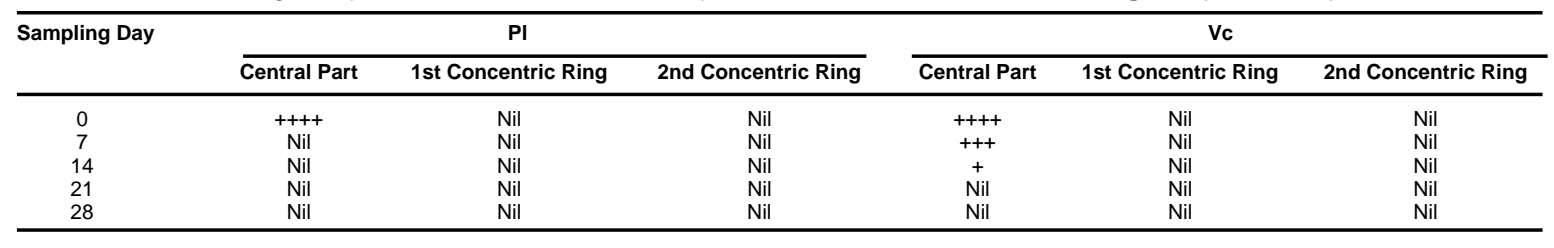

++++ Profuse Recovery, +++ Moderate Recovery, + Scanty Recovery

sterilized; Tarson India Ltd., Mumbai, India) containing $0.02 \%$ tetracycline $(\mathrm{w} / \mathrm{v})$ added after autoclaving of the media to prevent bacterial growth and maintained at $26^{\circ} \mathrm{C}$. The predatory activity of the fungi was checked by egg bait assay using mixture of live eggs of F. gigantica and G. explanatum (De et al., 2008). The fungi were then grown in solid substrate (millet grains) by putting a piece of corn meal agar medium containing fungal growth to a flask containing autoclaved millet grains (Sanyal, 2000) and incubated at $26^{\circ} \mathrm{C}$ for 6 weeks, the flask being shaken twice weekly for six weeks to get uniform growth. Fungal spread: Four $1 \mathrm{~m}^{2}$ pasture plots, each separated by a meter and mowed to a grass height of $10 \mathrm{~cm}$, were prepared in a pasture never grazed by animals for the last five years. At the center of a plot, in replicates of two, two $\mathrm{kg}$ goat faeces mixed with $100 \mathrm{gm}$ fungal grain culture of $V$. chlamydosporium was deposited. Similarly, in another two plots faeces containing $P$. lilacinus grain culture was deposited. Two concentric rings of goat faeces without fungal grain culture were prepared at the distance of 1 and 2 feet from central deposition in each plot. Plots were maintained in moist condition by spray irrigation for one month. Coproculture (Sanyal, 2000) of the fungus contaminated plots, both from central part and two concentric rings, were undertaken twice a week for four weeks in laboratory for reisolation of V. chlamydosporium and P. lilacinus. The culture plates were baited with live eggs of $F$. gigantica and G. explanatum. Subcultures of the suspected fungi were made in corn meal agar till the confirmation of the desired fungi by morphology and morphometry (Samson, 1974).

Faeceal decomposition: In two separate pasture plots, goat faeces $(5 \mathrm{~kg})$ mixed with millet grain culture of V. chlamydosporium and P. lilacinus at 100 gm kg- ${ }^{1}$ faeces were deposited. Simultaneously, in a control plot only five $\mathrm{kg}$ goat faeces was deposited. From these plots, faecal decomposition over time with or without fungal baiting was measured twice a month for 3 months by determining percentage of moisture, dry matter, ash and organic matter content of faeces by conventional techniques (AOAC, 1995).
Statistical analysis: The data were analysed by analysis t-test using GraphPad Prism 4 software (Version 4.02, GraphPad Software Inc., 2004, USA).

\section{Results and Discussion}

Fungal spread: Results of reisolation of the egg parasitic fungi from faeces mixed with millet grain cultures of $P$. lilacinus and $V$. chlamydosporium are presented in Table 1 . While P. lilacinus could not be reisolated from the central part and two concentric rings at any point of sampling period except on the day of deposition (day-0) from the central part, $V$. chlamydosporium could be re-isolated from the faeces deposited at the central part on day 0,7 and 14 but never from $21^{\text {st }}$ day onward. However, $V$. chlamydosporium could not be recovered from the faeces of two concentric rings at any point of sampling period. Needless to add that the faecal recovery of $V$. chlamydosporium on the coproculture was showing decreasing trend as the days progressed (Table 1). It is well known that predacious fungi are relatively poor competitors with other saprophytic fungi in soil/grass (Baron, 1977). Further, along with deposition egg parasitic fungi in the faeces, colonization of coprophilic organisms from the external environment would also be expected to occur resulting in species competition and death of artificially introduced fungi (Bell, 1983). The present study also revealed that $P$. lilacinus was a very poor species competitor compared to that of $V$. chlamydosporium as evidenced by the failure of its reisolation from the faeces. Faecal decomposition: Moisture, dry matter, ash and organic matter content of faeces mixed with millet grain cultures of $P$. lilacinus and $V$. chlamydosporium and no fungus controls are presented in Table 2 . The moisture contents decreased with corresponding increase in dry matter content of the faeces as the time progressed. Unusual observations in moisture and dry matter contents of the faeces were recorded on day 75 and 90 of the sampling period. Onset of monsoon rains with the resultant drenching of pasture plots could serve as the possible explanation. On the contrary, ash and organic matter contents of faeces revealed consistent results (Table 2). From $60^{\text {th }}$ day of deposition onwards, 
Fungal spread and faecal decomposition as indicators to evaluate environmental impact of egg parasitic fungi

Table-2. Moisture, dry matter, ash and organic matter contents of faeces (Mean \pm SEM) mixed with millet grain cultures of P. lilacinus ( PI), V. chlamydosporium ( Vc) and no fungus controls (Cont.)

\begin{tabular}{|c|c|c|c|c|c|c|c|c|c|c|c|c|}
\hline \multirow[t]{2}{*}{ Days } & \multicolumn{3}{|c|}{ Moisture (\%) } & \multicolumn{3}{|c|}{ Dry Matter (\%) } & \multicolumn{3}{|c|}{ Ash (\%) } & \multicolumn{3}{|c|}{ Organic matter (\%) } \\
\hline & PI & Vc & Cont. & PI & Vc & Cont. & PI & Vc & Cont. & PI & Vc & Cont. \\
\hline $\begin{array}{l}0 \\
15 \\
30 \\
45 \\
60 \\
75 \\
90\end{array}$ & $\begin{array}{l}8.0+1.0 \\
7.0+2.0 \\
7.5+0.5 \\
59.5+1.5 \\
65.0+4.0 \\
41.0+2.0 \\
62.5+6.5\end{array}$ & $\begin{array}{l}7.0+1.0 \\
6.5+0.5 \\
8.5+0.5 \\
57.5+2.5 \\
69.5+2.5 \\
18.0+2.0 \\
65.5+5.5\end{array}$ & $\begin{array}{l}8.0+2.0 \\
6.0+1.0 \\
4.5+0.5 \\
59.0+1.0 \\
63.5+2.5 \\
40.0+2.0 \\
70.0+3.0\end{array}$ & $\begin{array}{l}92.0+2.0 \\
93.0+6.0 \\
92.5+2.5 \\
40.5+3.5 \\
35.0+1.0 \\
59.0+1.0 \\
37.5+0.5\end{array}$ & $\begin{array}{l}93.0+3.0 \\
93.5+2.5 \\
91.5+0.5 \\
42.5+2.5 \\
30.5+0.5 \\
82.0+3.0 \\
34.5+2.5\end{array}$ & $\begin{array}{l}92.0+3.0 \\
94.0+2.0 \\
95.5+2.5 \\
41.0+1.0 \\
36.5+2.5 \\
60.0+4.0 \\
30.0+2.0\end{array}$ & $\begin{array}{l}19.0+1.0 \\
22.0+3.0 \\
20.5+1.5 \\
12.0+1.0 \\
19.5+0.5 \\
32.0+3.0 \\
41.5+1.5\end{array}$ & $\begin{array}{l}16.0+6.0 \\
22.5+4.5 \\
21.5+4.5 \\
17.5+2.5 \\
31.0+1.0 \\
43.5+2.5 \\
45.5+3.5\end{array}$ & $\begin{array}{l}21.0+2.0 \\
24.0+2.0 \\
24.5+0.5 \\
21.5+2.5 \\
24.0+2.0 \\
26.0+2.0 \\
40.5+1.5\end{array}$ & $\begin{array}{l}81.0+1.0 \\
78.0+3.0 \\
79.5+1.5 \\
88.0+1.0 \\
80.5+4.5 \\
68.0+3.0 \\
58.5+1.5\end{array}$ & $\begin{array}{l}84.0+0.0 \\
77.5+0.5 \\
78.5+4.5 \\
82.5+2.5 \\
69.0+1.0 \\
56.5+2.5 \\
54.5+1.5\end{array}$ & $\begin{array}{l}79.0+7.0 \\
76.0+2.0 \\
75.5+0.5 \\
78.5+2.5 \\
76.0+2.0 \\
74.0+2.0 \\
59.5+1.5\end{array}$ \\
\hline
\end{tabular}

ash contents of faeces mixed with P. lilacinus, $V$. chlamydosporium and no fungus controls showed increasing trend with the corresponding decreasing trends in organic matter contents. Dung decomposition rate is useful parameter in measuring biotic activity of natural dung-dwelling microorganisms including soil nematodes. Any adverse effect of egg parasitic fungi on these organisms would possibly be resulted in changes in biotic factors like aeration, for further breakdown of faeces by earthworms and microbial decomposition (Sommer et al., 1992). The adverse effect, if any, would possibly have resulted in persistently increased organic matter content of the faeces. This was never happened in the present study. It has already been demonstrated that nematode-trapping fungus Duddingtonia flagrans exhibited no adverse effect on faecal decomposition rate with unaltered moisture, dry matter, ash and organic matter content of the faeces over a period of 90 days (Sanyal and Mukhopadhyaya, 2003). Yeates et al. (1997) examined the effects of D. flagrans on nematode dynamics over a period of seven and half months and compared their activity in presence or absence of $D$. flagrans. They observed no significant differences in soil nematode population between the two treatments and envisaged no detrimental impact on soil fertility by nematophagous fungi. Dimander $e t$ al (2003) reported no difference in cattle dung disintegration in D. flagrans baited faecal pat. Dung pats disappeared within 2 weeks when subjected to heavy rainfall early after deposition, whereas an extended dry period coincided with faeces still remaining 12 months after deposition. The results of the present study provided evidence that the egg parasitic fungi, P. lilacinus and $V$. chlamydosporium exhibited no significant short-term adverse impact on its immediate micro-environment.

\section{Acknowledgement}

The research was the result of All India Network Project on Gastrointestinal Parasitism of Indian Council of Agricultural Research. Facilities provided by the Dean, College of Veterinary Science \& AH, Anjora, Durg are thankfully acknowledged.

\section{References}

1. AOAC. (1995). Official Methods of Analysis. $16^{\text {th }}$ edn Association of Official Analytical Chemists, Washington, D.C.

2. Barron, G.L. (1977). The Nematode-destroying fungi. Topic in Microbiology No. 1,

3. Bell, A. (1983). Dung Fungi : An illustrated guide to coprophilous fungi in New Zealand. Victoria University Press, Weelington, NZ.

4. De, S., Sanyal, P.K., Sarkar, A.K., Patel, N.K., Pal, S. and Mandal, S.C (2008). Screening for Indian isolates of egg parasitic fungi for use in biological control of fascioliasis and amphistomiasis in ruminant livestock. J. Helminthol., 82 : 271-277.

5. Dimander, S.O., Höglund, J. and Waller, P.J. (2003). Disintegration of Dung Pats from Cattle Treated with the Ivermectin Anthelmintic Bolus, or the Biocontrol Agent Duddingtonia flagrans. Acta Vet. Scand., 44 : 171-180.

6. Larsen, M. (1999). Biological control of helminths. Inter. J. Parasitol., 29: 139-146.

7. Samson, R.A. (1974). Paecilomyces and some allied hyphomycetes. Studies in Mycol. No. 6, pp. 119, Centraalbureau Voor Schimmelcultures, Baarn.

8. Sanyal, P.K. (1998). Integrated parasite management in ruminants in India : A concept note. Biological control of gastro-intestinal parasites of ruminants using predacious fungi, FAO Anim. Prod. Hlth. Paper 141:54-65.

9. Sanyal, P.K. (2000). Screening for Indian isolates of predacious fungi for use in biological control against nematode parasites of ruminants. Vet. Res. Comm., 24:55-62.

10. Sanyal, P.K. and Mukhopadhyaya, P.N. (2003). Fungal spread on pasture and faecal decomposition as parameters to evaluate short-term environmental impact of Duddingtonia flagrans. J. Vet. Parasitol., 17 :32-36.

11. Sanyal, P.K., De, S., Sarkar, A.K., Patel, N.K., Mandal, S.C and $\mathrm{Pal}, \mathrm{S}$. (2008). Isolation of egg parasitic fungi from Chhattisgarh. J. Vet. Parasitol., 22:1-3.

12. Sommer, C., Steffansen, B., Overgaard Nielsen, B. Gronvold, J., Vagn Jensen, K.M., Brochner Jespersen, J, Springborg, J. and Nansen, P. 1992. Ivermectin excreted in cattle dung after subcutaneous injection or pour-on treatment: concentrations and impact on dung fauna. Bull. Entomol. Res., 82:257-264.

13. Stirling, G.R. (1991). Antagonist of Nematodes. Ch.4. In: G.R. Stirling (Ed.), Biological control of Plant Parasitic Nematodes. CAB International, Wallingford, UK, pp. 50-98.

14. Waller, P.J. (1993). Towards sustainable nematode parasite control of livestock. Vet. Parasitol., 48 : 295-309.

15. Yeates, W.P., Waller, P.J. and King, K.L. (1997). Soil nematodes as indicators of the effects of management on grasslands in the New England Tablelands (NSW): effect of measures for control of parasites of sheep. Pedobiologia 41 : 537-548.

$* * * * * * * *$ 